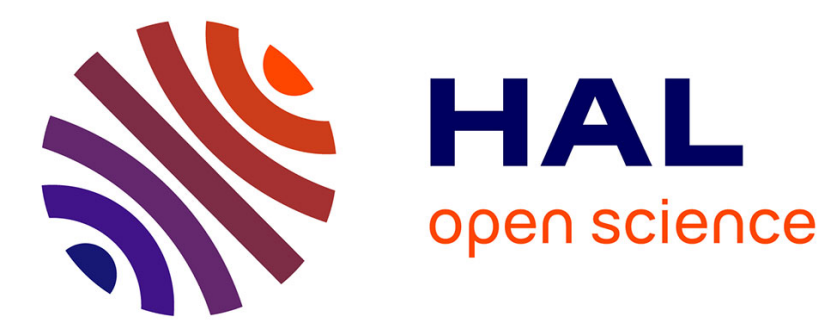

\title{
Carbon-based Nanosensors for Salicylate Determination in Pharmaceutical Preparations
}

Fatehy Abdel-haleem, Azza Salah, Mahmoud Rizk, Hussein Moustafa, Mikhael Bechelany, Ahmed Barhoum

\section{- To cite this version:}

Fatehy Abdel-haleem, Azza Salah, Mahmoud Rizk, Hussein Moustafa, Mikhael Bechelany, et al.. Carbon-based Nanosensors for Salicylate Determination in Pharmaceutical Preparations. Electroanalysis, 2019, 31 (4), pp.778-789. 10.1002/elan.201800728 . hal-02127059

\section{HAL Id: hal-02127059 \\ https://hal.umontpellier.fr/hal-02127059}

Submitted on 3 Jun 2021

HAL is a multi-disciplinary open access archive for the deposit and dissemination of scientific research documents, whether they are published or not. The documents may come from teaching and research institutions in France or abroad, or from public or private research centers.
L'archive ouverte pluridisciplinaire HAL, est destinée au dépôt et à la diffusion de documents scientifiques de niveau recherche, publiés ou non, émanant des établissements d'enseignement et de recherche français ou étrangers, des laboratoires publics ou privés. 


\title{
Carbon-based nanosensors for salicylate determination in
}

\section{pharmaceutical preparations}

Fatehy M. Abdel-Haleemª,* Azza Salah ${ }^{\mathrm{a}}$, Mahmoud S. Rizk ${ }^{\mathrm{a}}$, Hussein Moustafa ${ }^{\mathrm{a}}$, Mikhael

\author{
Bechelany $^{\mathrm{b}}$, Ahmed Barhoum ${ }^{\mathrm{b}, \mathrm{c}^{*}}$
}

${ }^{a}$ Chemistry Department, Faculty of Science, Cairo University, Gamaa Street, Giza 12613, Egypt.

${ }^{\mathrm{b}}$ Institut Européen des Membranes, IEM - UMR 5635, ENSCM, CNRS, Univ Montpellier, Montpellier, France.

${ }^{\mathrm{c}}$ Department of Materials and Chemistry, Vrije Universiteit Brussel, B-1050 Brussels, Belgium.

*Corresponding author: fatehy@sci.cu.edu.eg, ahmed.barhoum@science.helwan.edu.eg;

ahmed.abdelrasoul@vub.ac.be

\begin{abstract}
Thiourea-based carbon paste electrodes (CPEs) were constructed as potentiometric sensors for the determination of salicylate anion in pharmaceutical preparations. The optimized CPE consists of $45.5 \%$ graphite, $0.5 \%$ reduced graphene oxide $(\mathrm{rGO}), 46 \%$ plasticizer, $5 \%$ thiourea ionophore, and $3 \%$ tridodecylmethyl ammonium chloride as additive. The electrode exhibited a Nernstian response of 59 $\mathrm{mV}$ decade ${ }^{-1}$ in the concentration range of $10^{-1}-10^{-5}$ mole $\mathrm{L}^{-1}$ and a detection limit of $1 \times 10^{-5}$ mole $\mathrm{L}^{-1}$. The prepared sensor showed high selectivity against similar anions (i.e. $\mathrm{ClO}_{4}^{-}$, benzoate, $\mathrm{I}^{-}, \mathrm{SCN}^{-}$). Selectivity was confirmed by calculating formation constant $(\beta)$ using sandwich membrane method, where $\beta$ for thiourea-salicylate is $10^{0.43}$. The selectivity, the molecular recognition mechanism and the bonding interaction between the salicylate anion and the nitrogen-rich ionophore were studied and quantified by performing theoretical calculations at DFT-B3LY/6-31G** level of theory. The sensors can be successfully used for the determination of salicylate anion in different pharmaceutical formulations, Aspocid® and Aspirin $®$.
\end{abstract}


Keywords: Potentiometric sensors; salicylate; reduced graphene oxide; thiourea; DFT; nonlinear optical properties.

\section{Introduction}

Salicylate is the salt of a salicylic acid that occurs naturally in plants or synthetically in medications, perfumes or preservatives [1]. Salicylate works as a preservative and natural immune hormone of the plant, thus protecting the plant against fungi, insects and different diseases [1]. In human medications, salicylate is used as inflammatory, antimicrobial and analgesic agent and as heart attack protective. It reduces pain and fever and may protect against colon cancer [2, 3]. However, the high doses of salicylate lead to accidental poisoning death of children, bleeding; Reye's syndrome and its long use may cause kidney cancer and liver diseases [4]. So, determination of salicylate concertation in plasma is crucial. Also, monitoring its concentration in pharmaceutical and biological samples is important, as salicylate becomes toxic in blood when exceeds $2.2 \times 10^{-3} \mathrm{mmole} \mathrm{L}^{-1}(300 \mathrm{mg} / \mathrm{L})[5,6]$, while the effective therapeutic dose range is from $1.1 \times 10^{-3}$ to $2.2 \times 10^{-3} \mathrm{mmole}^{-1}$, which is too close to the toxicity level. Salicylate concentration higher than $4.3 \times 10^{-3} \mathrm{mmole}^{-1}$ is considered as lethal dose [7].

To date, various methods have been developed for the determination of salicylate in physiological fluids, including fluorometry [8], UV spectrophotometry [9-10], flow-injection atomic absorption spectrometry [11], voltammetry [12] and high-performance liquid chromatography (HPLC) [13]. However, most of these methods are expensive, tedious, lake adequate selectivity, and timeconsuming. To overcome these drawbacks, electrochemical techniques such as potentiometric sensors were recently used for routine analysis. Potentiometric sensors are applicable for determining salicylate (charged species) in colored and turbid solutions, e.g. physiological fluids and pharmaceutical formulations. The potentiometric sensors and their ion-selective electrodes respond to the analytes in the presence of various interfering ions. Other advantages characterize potentiometric 
sensors over other analytical techniques such as applicability over wide concentration ranges, low detection limit and fast response time which facilitate the use of potentiometric sensors in routine work [14].

Different types of ion-selective electrodes (ISEs) such as poly(vinyl chloride) (PVCE), carbon paste (CPE), modified carbon paste (MCPE), and screen-printed electrodes (SPE) have been used in potentiometric sensors. CPEs and MCPEs acquire certain importance due to its simplicity over other types, the variability in size and the possibility of miniaturization, the renewability of the sensor surface, the ease of construction and the possibility of modification [15]. Different modifiers were used for the improvement of the response characteristics of the constructed sensors, such as lipophilic ionexchanger (e.g. derivatives of tetraphenyl borates or quaternary ammonium salts), carbon nanotubes (CNTs), graphene and reduced graphene oxide (rGO) [16,17].

Up to date, several potentiometric sensors have been reported for salicylate determination [18-22]. However, these sensors lack adequate selectivity, need long response time, are applied in a small concentration range, and some of them use expensive ionophores [18-21]. Thiourea is commercially available reagents [22,23] and forms very stable complexes with salicylate [24,25]. It has been used for the optical detection of salicylate [26]. However, the optical detection of salicylate using thioureabased sensor suffered from small concentration range $\left(10^{-1}-10^{-4}\right.$ mole $\left.^{-1}\right)$, high detection limit $\left(3.9 \times 10^{-}\right.$ ${ }^{5}$ mole $\left.\mathrm{L}^{-1}\right)$, and long response time (2-3 minutes) [26].

In this study, we report straightforward a precise thiourea-based rGO-modified CPE for the determining of salicylate in pharmaceutical formulations. Incorporation of thiourea into the ISEs for the electrochemical detection of salicylate overcomes the early reported sensors [18-22,26], and exhibited better selectivity over early reported thiourea-based sensor [27]. The mechanism of the complex formation is investigated theoretically. The geometries of the studied complexes are stabilized by the formation of H-bonds. The energies calculated for HOMO and LUMO ( $\mathrm{E}_{\text {HOMO }}$ and $\mathrm{E}_{\mathrm{LUMO}}$ ) of 
the studied complexes are used to find the different global properties. The prepared sensors were used for determining the salicylate in real pharmaceutical formulations, Aspocid®, and Aspirin $®$. The bonding interaction between the salicylate anion and the nitrogen-rich ionophore were studied and quantified by performing theoretical calculations at DFT-B3LY/6-31G** level of theory. The electronic dipole moment $(\mu)$ and first-order hyperpolarizability $(\beta)$ values of the formed complexes have been computed theoretically [28, 29].

\section{Experimental}

\section{Materials}

Graphite $(\mathrm{G}, 99.9 \%,<45 \mu \mathrm{M})$, multiwalled carbon nanotubes (NC7000 ${ }^{\mathrm{TM}}$ - Nanocyl) sodium borohydride $\left(\mathrm{NaBH}_{4}, 98 \%\right)$, poly(vinyl chloride) with high molecular weight (Mw 43,000) (PVC), 4,5-dimethyl-1,2 -phenylendiamine (DMPD, 98\%), 4-nitro-phenyl isothiocyanate (NPTC, 98\%), tetrahydrofuran (THF, 99.9\%), tridodecyl-methylammonium chloride (TDMAC, 98\%), graphene oxide (GO nanosheets), different plasticizers like, dibutyl 2-nitrophenyloctyl ether (O-NPOE, 99\%), and dioctyl phthalate (DOP, 99.5\%) were of analytical grade and purchased from Sigma-Aldrich (Munich, Germany). Doubly distilled water was used through this work. Glacial acetic acid (99.5\%), sodium hydroxide, silver nitrate, chloroform, petroleum ether, hydrochloric acid (30\%), acetone, sodium salts of sulfate, nitrate, nitrite, chloride, iodide, bromide, benzoate, salicylate, thiocyanate and perchlorate monohydrate were purchased from ADWIC (Cairo, Egypt), and used as received without further purification. Sodium acetate solution $\left(0.05\right.$ mole $\left.\mathrm{L}^{-1}\right)$ with $\mathrm{pH}(4.5)$ and 0.05 mole $\mathrm{L}^{-1}$ phosphate buffers ( $\mathrm{pH}$ 7) were used for the preparation of salicylate and different interfering anions solutions [30].

\section{Preparation of reduced graphene oxide and thiourea}


Reduced graphene oxide (rGO) was prepared by the reduction of GO using $\mathrm{NaBH}_{4}$ [31]. Briefly, approximately $1.0 \mathrm{~g}$ of $\mathrm{GO}$ was dispersed in $50 \mathrm{~mL}$ of $10 \mathrm{mM} \mathrm{NaBH}_{4}$, sonicated for $1 \mathrm{~h}$, and centrifuged to separate the rGO nanosheets. The coagulate was then dried at $120{ }^{\circ} \mathrm{C}$. The thiourea ionophore was prepared as described elsewhere [27]. Briefly, DMPD:NPTC with a mole ratio of 1:2 were dissolved in methanol and then the reaction mixture was refluxed for $4 \mathrm{~h}$. Yellow powder of thiourea was obtained after filtration, washing and drying at $100{ }^{\circ} \mathrm{C}$.

\section{Apparatus and characterization techniques}

Morphology of the constructed sensors was examined by Scanning Electron Microscopy (SEM, Zeiss EVO HD-15) coupled with an Oxford X-MaxN EDX detector. The elemental distribution (composition) was mapped through energy dispersive X-Ray spectroscopy (EDX) by integrating the intensity of the peaks corresponding to $\mathrm{C}, \mathrm{N}, \mathrm{O}, \mathrm{S}$, and $\mathrm{Cl}$ as a function of the beam position when operating the SEM in scanning mode.

Bonding structures were analyzed using Fourier transform infrared spectroscopy (FTIR, Filter460 plus JASCO); $\mathrm{KBr}$ pellets were used for the measurement and spectra were taken in the range $4000-400 \mathrm{~cm}^{-1}$. Structure and purity were characterized and ensured by Thin-layer chromatography (TLC), Gas-chromatography-Mass spectrometry (GC-MS, SHIMADZU QP-2010, Japan) at 70 eV, FTIR and Proton-Nuclear magnetic resonance $\left({ }^{1} \mathrm{H}-\mathrm{NMR}\right.$, Mercury-300BB, USA) using d-DMSO as a solvent, as reported elsewhere [27]. For potential and pH measurements, digital Jenway 3010 and 3505 pH meters (England) were used. Home-made $\mathrm{Ag} / \mathrm{AgCl}$ as an internal reference electrode and saturated calomel reference electrode (SCE) (Hanna-Italy) was used as the outer reference electrode.

\section{Preparation of PVC and sandwich membrane electrodes}

PVC membrane was prepared from 33\% PVC, $66 \%$ plasticizer, and different percentages of TDMAC and thiourea (Table 1). The membrane constituents were dissolved in $3 \mathrm{~mL}$ THF, inside in 5 $\mathrm{cm}$ diameter Petri dish under continuous stirring. After drying in air for $24 \mathrm{~h}$, a homogenous transparent 
membrane was obtained [1,2]. The formed membrane was cut and glued to the end of PVC tube electrode using PVC/THF cocktail, filled with internal soaking solutions $(0.02 \mathrm{M} \mathrm{NaCl}+0.02 \mathrm{M}$ sodium salicylate) and then soaked for $24 \mathrm{~h}$. For the sandwich membrane, additional membrane without any ionophore (reference membrane MR) was prepared by the same method and stuck by hand to the other ionophore-containing membrane [3]. The sandwich membrane was glued to the end of the PVC tube, and filled with internal soaking solutions in the same way [3].

\section{Preparation of carbon paste ISEs}

Unmodified CPEs were constructed by mixing thiourea, plasticizer, TDMAC, and graphite in an agate mortar and mixed well until it was uniformly wetted. In the case of modified CPEs, one of the different additives MWCNTs, GO or rGO) was added to the paste mixture before mixing for complete homogeneity [32]. Electrode body filled with the mixture and polished on a very smooth surface to get the shiny surface. Electrical contact is made through a stainless-steel rod through the center of the holder. The electrode could be used directly for potentiometric measurements without preconditioning.

\section{Electromotive force measurements and pH effect}

Potentiometric measurements were carried out using digital Jenway $3010 \mathrm{pH}$-meter (England) in which the potential difference or electromotive force (EMF) between ion selective working electrode (WE) and the reference saturated calomel electrode (RE) under zero current flow was measured at room temperature. The electrochemical system could be represented as (RE//Sample//WE) in which both electrodes were immersed in different anion concentrations. The obtained EMF values plotted against the logarithmic values of the different concentrations. According to Nernest Equation, EMF is proportional to the logarithm of the ion activity.

The $\mathrm{pH}$ effect on the potential measurements of salicylate selective electrodes was tested using $10^{-}$

${ }^{3}$ mole $\mathrm{L}^{-1}$ salicylate as a test solution. $\mathrm{pH}$ value was changed from 2 to 11 by the addition of $\mathrm{NaOH}$ or 
$\mathrm{HCl}$ to the test solution, and the EMF of this solution was recorded. EMF was plotted versus the different $\mathrm{pH}$ values.

\section{Selectivity coefficient determination}

Selectivity coefficient $K_{S a l, J}^{\text {pot }}$ was determined by separate solution method (SSM), in which EMF of a cell containing two solutions separately, one containing the salicylate at the activity asal (but no interfering $\mathrm{J}$ ), and the other containing the interfering ion $\mathrm{J}$ at the same activity $\mathrm{a}_{\mathrm{J}}=\mathrm{a}$ al (but no salicylate). The value of $K_{S a l, J}^{p o t}$ could be calculated from equation 1:

$$
K_{S a l, J}^{p o t}=\frac{E_{2}-E_{1}}{S}+\left(1-\frac{Z_{S a l}}{Z_{J}}\right) \log a_{S a l}
$$

Where $\mathrm{E}_{1}$ and $\mathrm{E}_{2}$ are the measured EMF values for $10^{-1}$ mole $\mathrm{L}^{-1}$ salicylate and interfering ion solutions, respectively, $\mathrm{Z}_{\mathrm{Sal}}$ and $\mathrm{Z}_{\mathrm{J}}$ are the charges of salicylate and the interfering anions, respectively, and $\mathrm{S}$ is the slope of the calibration curve.

\section{Formation constant measurements and calculations}

Strength of the binding between ionophore and different anions are estimated by determining the complex formation constants in the membrane phase. Two membranes, one with ion-exchanger and ionophore and another one containing only the ion-exchanger were prepared. One of the membranes was placed on top of the other and the potential across the sandwiched membrane was measured potentiometrically. The formation constant $\left(\beta_{I L_{n}}\right)$ was calculated using equation 2 :

$$
\beta_{I L_{n}}=\left(L_{T}-\frac{n R_{T}}{Z_{I}}\right)^{-n} \exp \left(\frac{E_{M} Z_{I} F}{R T}\right)
$$

where $\mathrm{T}$, the absolute temperature; $\mathrm{R}$, the gas constant; $\mathrm{F}$, the Faraday constant; $\mathrm{L}_{\mathrm{T}}$, the total concentration of thiourea ionophore in the membrane segment; $\mathrm{R}_{\mathrm{T}}$, the concentration of TDMAC; $\mathrm{Z}_{\mathrm{I}}$, the charge of the anion I; $n$, the stoichiometry of the ion-ionophore complex: and $\mathrm{E}_{\mathrm{M}}$, the membrane 
potential. The $\mathrm{E}_{\mathrm{M}}$ value depends mainly on the host-guest interaction and it can be determined by subtracting the cell potential of the membrane without ionophore from that of the sandwich membrane. The values of the formation constant could be related to the selectivity coefficients values.

\section{Computational study}

The gaussian 09W software package was used for performing all computational studies [33]. Molecular geometries of all the studied complexes were fully optimized using B3LYP/6-311G** [34-36]. No symmetry constraints were applied during the geometry optimization [37,38]. The electronegativity and chemical hardness were calculated as follows: $\eta=(I-A) / 2 \quad$ (chemical hardness), $X=(I+A) / 2 \quad$ (electronegativity), $S=1 / 2 \eta \quad$ (chemical softness) using the HOMO and LUMO energy values for a complex. Where I and A are ionization potential and electron affinity, and $\mathrm{I}=-\mathrm{E}_{\mathrm{HOMO}}$ and $\mathrm{A}=-\mathrm{E}_{\mathrm{LUMO}}$, respectively. Throughout this work, MOs were constructed using the Gauss-view 5.08 visualization program. The mean polarizability $\langle\alpha\rangle$, the anisotropy of the polarizability $\Delta \alpha$, total static dipole moment $(\mu)$, and the mean first hyperpolarizability $<\beta>$ using the $x, y, \quad z$ components were calculated by using the following equations 3-7:

$$
\begin{gathered}
\alpha=\frac{\left(\alpha_{X X}+\alpha_{Y Y}+\alpha_{Z Z}\right)}{3} \\
\Delta \alpha=\sqrt{\left[\frac{\left(\alpha_{X X}-\alpha_{Y Y}\right) 2+\left(\alpha_{Y Y}-\alpha_{Z Z}\right) 2+\left(\alpha_{Z Z}-\alpha_{X X}\right) 2}{2}\right]} \\
\mu=\left(\mu_{\mathrm{x}}{ }^{2}+\mu_{\mathrm{y}}{ }^{2}+\mu_{\mathrm{z}}{ }^{2}\right)^{1 / 2} \\
<\beta>=\beta_{\mathrm{x}}{ }^{2}+\beta_{\mathrm{y}}{ }^{2}+\beta_{\mathrm{z}}{ }^{2} \\
\text { where, } \beta_{\mathrm{x}}=\beta_{\mathrm{xxx}}+\beta_{\mathrm{xyy}}+\beta_{\mathrm{xzz},} \quad \beta_{\mathrm{y}}=\beta_{\mathrm{yyy}}+\beta_{\mathrm{xxy}}+\beta_{\mathrm{yzz}, \quad} \quad \beta_{\mathrm{z}}=\beta_{\mathrm{zzz}}+\beta_{\mathrm{xxz}}+\beta_{\mathrm{yyz}}
\end{gathered}
$$


Among second-order NLO phenomena, we focused on the hyper-Rayleigh scattering $\left(\beta_{\mathrm{HRS}}\right)$ response [39]. Assuming a non-polarized incident light in the X-direction, the harmonic light intensity scattered at $90^{\circ}$ in the $\mathrm{Y}$ direction and vertically (V) polarized (along the $\mathrm{Z}$ axis) is given by Bersohn's expression [40]:

$$
\beta_{\mathrm{HRS}}=\sqrt{\left(\beta_{Z Z Z}^{2}+\beta_{Z X X}^{2}\right)}
$$

The depolarization ratio, DR, which reveals the shape of the NLO-phore, reads

$$
\mathrm{DR}=\frac{\beta_{Z Z Z}^{2}}{\beta_{Z X X}^{2}}
$$

are orientational averages of the $\beta$ tensor, which are proportional to the scattered signal intensities for vertically and horizontally-polarized incident signals, respectively.

\section{Sample analysis}

The constructed sensors were examined for the determination of salicylate anion in different pharmaceutical formulations, i.e. Aspocid® $(75 \mathrm{mg})$ and Aspirin ${ }^{\circledR}(320 \mathrm{mg})$. Aspirin is a derivative of salicylic acid and is also known as acetylsalicylic acid. Aspirin ${ }^{\circledR}$ is a well-known drug for treating inflammation, fever, and pain and avoiding strokes risk. Aspocid ${ }^{\circledR}$ tablet is used for Risk of stroke, Fever, Rheumatic fever, Pain, Kawasaki disease, Rheumatoid arthritis, Pericarditis, Heart attack

Aspirin ${ }^{\circledR}$ and Aspocid ${ }^{\circledR}$ were prepared from their pharmaceutical preparations by grinding five tablets of each type to a fine powder. A known amount of tablets powder was dissolved in a buffer solution at $40{ }^{\circ} \mathrm{C}$ for 10 minutes and then cooled and filtered. Afterward, the buffer was completed with the buffer solution to $250 \mathrm{~mL}$. Other concentrations were obtained by appropriate dilutions. These solutions were used further for potentiometric determination of salicylate concertation using sensors of optimized conditions, and results were compared to that obtained with the reference methods $[27,41]$. 


\section{Results and discussion}

Primary studies were carried out using a carbon paste sensor containing thiourea as an ionophore. The response for all anions was weaker than that for salicylate anion, which confirms the specific interaction of thiourea with salicylate. These results were ensured by the previously reported method that used the same ionophore [27].

\section{Effect of the electrode composition}

Optimization of the working electrodes (ISEs) composition is the base for attaining highly responsive sensors. Thus, the effects of the carbon paste composition, type and amount of the plasticizer on potential characteristics of the sensor were investigated. Sensors 1-4 (Table) made of neutral thiourea (ionophore), TDMAC (ion-exchanger), and graphite and o-NPOE plasticizer (carbon past). Sensors 1-4 were tested to select the best (TDMAC/thiourea) mole ratio. The low mole ratio of about $15 \%$ in sensor 1 exhibited small response $\left(-27.7 \mathrm{mVdecade}^{-1}\right)$ in a reliable concentration range of $10^{-1}-10^{-5} \mathrm{M}$. Increasing this mole ratio from $40 \%$ to $50 \%$ in sensors 3 and 4 increased the slope of the sensors to about $-35 \mathrm{mVdecade}{ }^{-1}$. To reach Nernstian response, different modifiers $(\mathrm{GO}, \mathrm{rGO}$, and MWCNTs) were used in sensors 5-7 (Table 1). The high surface area and electrical conductivity of GO, rGO, and MWCNTs make these carbon-based materials as suitable modifiers.

Table 1: composition of different carbon paste electrodes

$$
\text { Composition (wt\%) } \quad \text { Response }
$$

Sensor

$$
\mathrm{G}^{\mathrm{a}} \quad \mathrm{P}^{\mathrm{b}} \quad \mathrm{I}^{\mathrm{c}} \quad \mathrm{A}^{\mathrm{d}}(\mathrm{mole} \%) \text { Carbon Modifier Slope }{ }^{\mathrm{e}} \quad \text { D.L. }{ }^{\mathrm{f}} \quad \text { C.R. }{ }^{\mathrm{g}}
$$

\begin{tabular}{lllllllll}
\hline 1 & 48.3 & $48.2 \mathrm{NPOE}$ & 3.0 & $0.5(15 \%)$ & ----- & -27.7 & $1 \times 10^{-5}$ & $10^{-1}-10^{-5}$ \\
2 & 48.2 & $47.82 \mathrm{NPOE}$ & 3.0 & $1.0(30 \%)$ & ---- & -22.0 & $1 \times 10^{-4}$ & $10^{-1}-10^{-4}$ \\
3 & 47.8 & $47.82 \mathrm{NPOE}$ & 3.0 & $1.4(40 \%)$ & ---- & -35.2 & $1 \times 10^{-5}$ & $10^{-1}-10^{-5}$ \\
4 & 46.0 & $46.02 \mathrm{NPOE}$ & 5.0 & $3.0(50 \%)$ & ---- & -35.5 & $1 \times 10^{-5}$ & $10^{-1}-10^{-5}$ \\
5 & 45.5 & $46.02 \mathrm{NPOE}$ & 5.0 & $3.0(50 \%)$ & $0.5 \mathrm{GO}$ & -53.6 & $1 \times 10^{-5}$ & $10^{-1}-10^{-5}$ \\
6 & 45.5 & $46.02 \mathrm{NPOE}$ & 5.0 & $3.0(50 \%)$ & $0.5 \mathrm{rGO}$ & -59.0 & $1 \times 10^{-5}$ & $10^{-1}-10^{-5}$
\end{tabular}




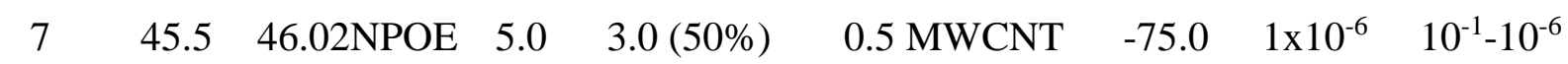
a: graphite, b: plasticizer, c: thiourea ionophore, d: TDMAC all the previous and modifier are in weight $\%$ ratio between moles of TDMAC to moles of thiourea is between brackets in A column. e: slope in $\mathrm{mVdecade}^{-1}, \mathrm{f}, \mathrm{g}$ : detection limit and concentration range in mole $\mathrm{L}^{-1}$.

The improvement in the slope by the addition of GO in sensor 5 can be explained by the existence of different hydroxyl and carboxylic function groups [31,42], that can enhance the formation of the hydrogen bond with salicylate anion. More improvement was achieved by addition of rGO in sensor 6, which is due to the high surface area and electrical conductivity of rGO that facilitate charge transfer and thus ensure high electrochemical activity, the populated chemical moieties on rGO surface which enhance the sensor performance, high tunability of the chemical and electrical properties of rGO, and efficient charge transport by rGO $[31,42,43]$. The larger surface area of the MWCNTs in sensor 7 may be the reason for the super-Nernstian response.

The nature of the plasticizer influences the dielectric constant of the past that affects the mobility within the past, which in turn affects the ion selective electrode characteristics $[44,45]$. Using plasticizer of high dielectric constant, o-NPOE, is preferred because it decreases the response time, increases the linear concentration range of application and decreases the detection limit (Fig. 1) [45]. We prepared sensor 8 that contains the same constituents of sensor 6 after replacing with a plasticizer of low dielectric constant, DOP. This change causes the deterioration of the sensing characters in terms of detection limit, concentration range and response time (Table 1). 


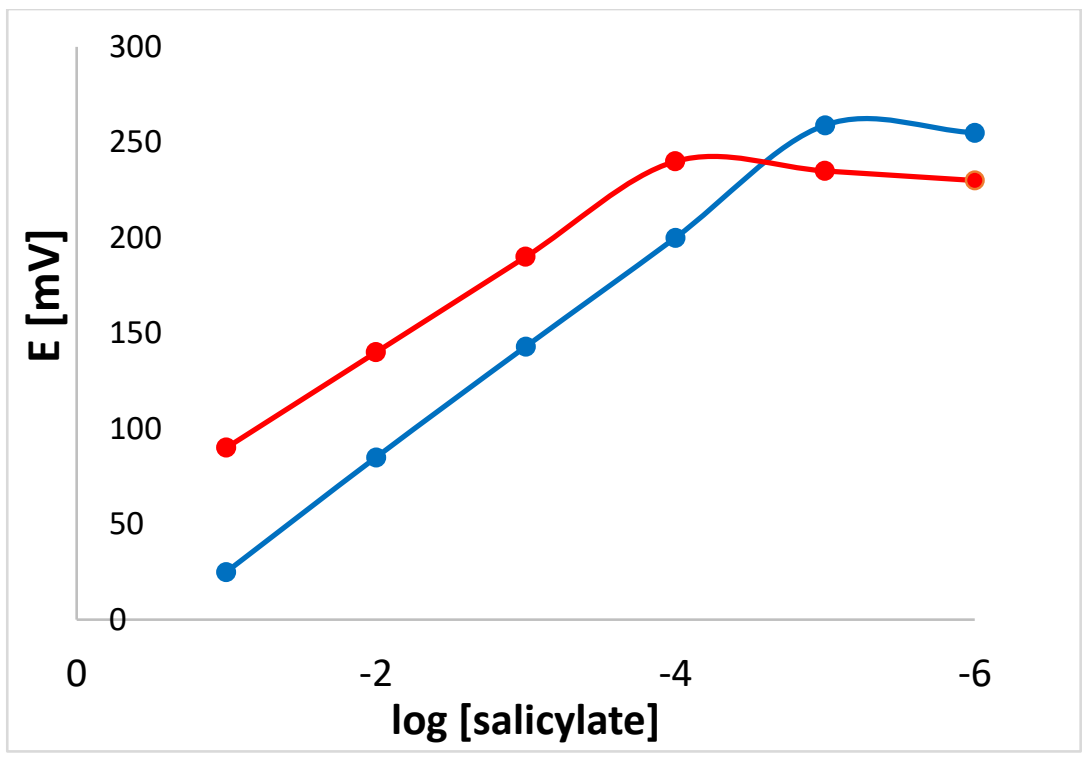

Fig. 1: Calibration curves of sensor 6 (blue) and sensor 8 (orange).

The morphology of the carbon paste electrodes (sensors 4-7) and the elemental distribution of nitrogen, oxygen, and sulfur in the carbon paste was investigated by SEM elemental mapping (Figure 2a-d). It can be seen clearly that elemental distribution of Nitrogen and Sulphur in the carbon paste (belong to thiourea ionophore ion-pair). The highest amount of carbon exists in sensor 4 which is mainly made of graphite. Addition of $\mathrm{GO}, \mathrm{rGO}$, and MWCNTs to carbon past increases the dispensability of thiourea ionophore, especially in the case of sensor 5 . Addition of $0.5 \mathrm{wt} \%$ GO to sensor 5 (Figure 5b) significantly improved the dispersion of the thiourea ionophore ion-pair in the carbon paste comparing with other sensors (Figure 1a). The relatively lower oxygen content in sensor 6 (Figure 2c and Table 2) comparing with sensor (5) indicates the reduction of GO into reduced GO. Addition of $0.5 \mathrm{wt} \%$ CNTs in the sensor 7 (Figure 5d) slightly improve the dispersion of the thiourea ionophore ion-pair in the carbon paste comparing with sensor 4 (Figure 1a). 
Table 2: percent of different elements in the elemental mapping of different sensors.

\begin{tabular}{|c|c|c|c|c|}
\hline $\begin{array}{c}\text { Elemental } \\
\text { composition }\end{array}$ & Sensor 4 & Sensor 5 & Sensor 6 & Sensor 7 \\
\hline $\mathrm{C}$ & 97.1 & 93.4 & 96.4 & 93.7 \\
\hline $\mathrm{N}$ & 0.0 & 1.1 & 0.4 & 0.5 \\
\hline $\mathrm{O}$ & 2.5 & 4.7 & 2.5 & 4.9 \\
\hline $\mathrm{S}$ & 0.4 & 0.8 & 0.7 & 0.9 \\
\hline
\end{tabular}

(a)

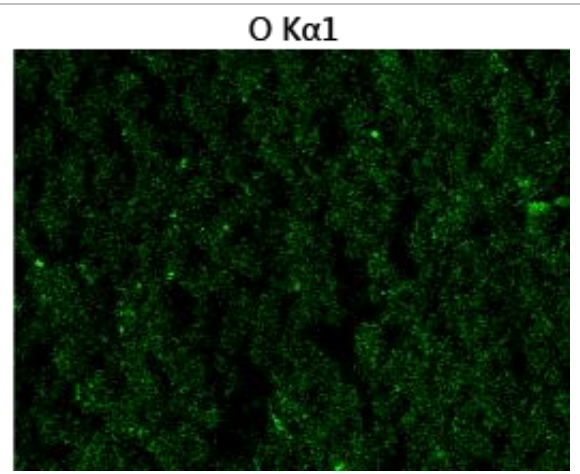

(b)
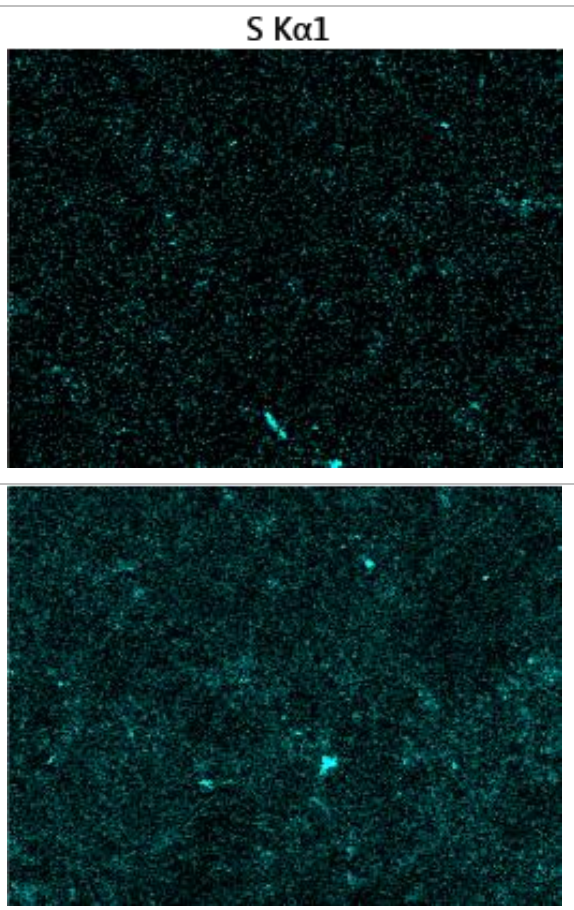

N Ka1_2
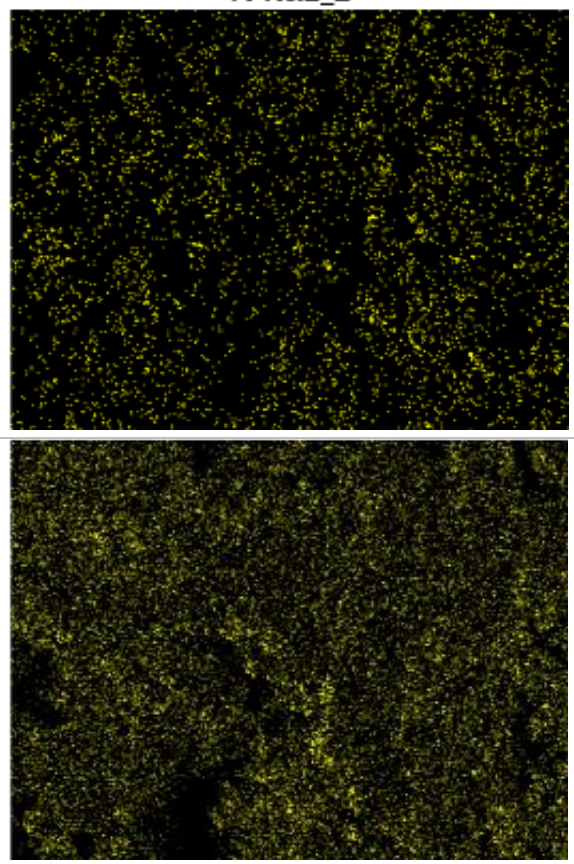

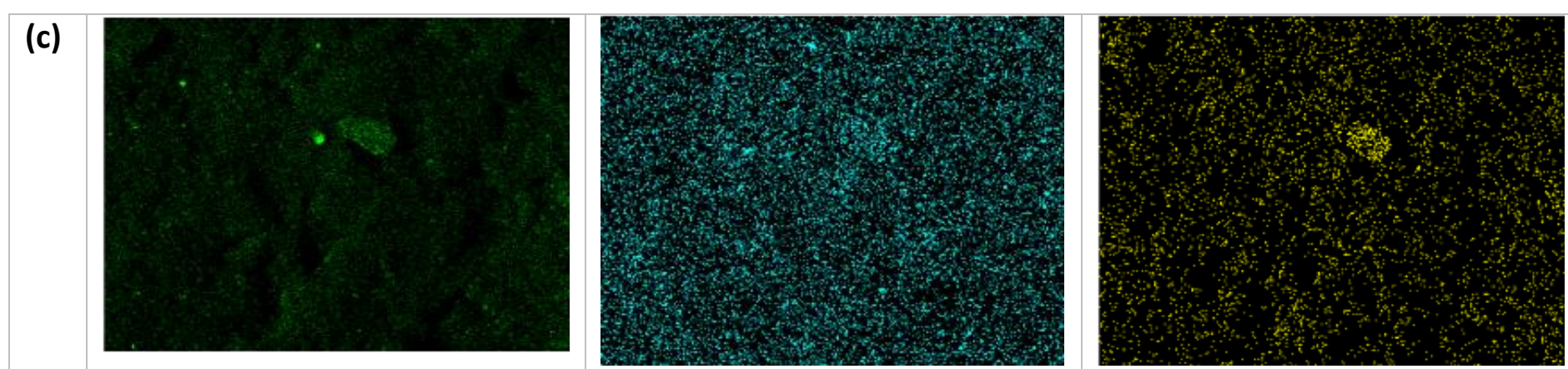

(d)
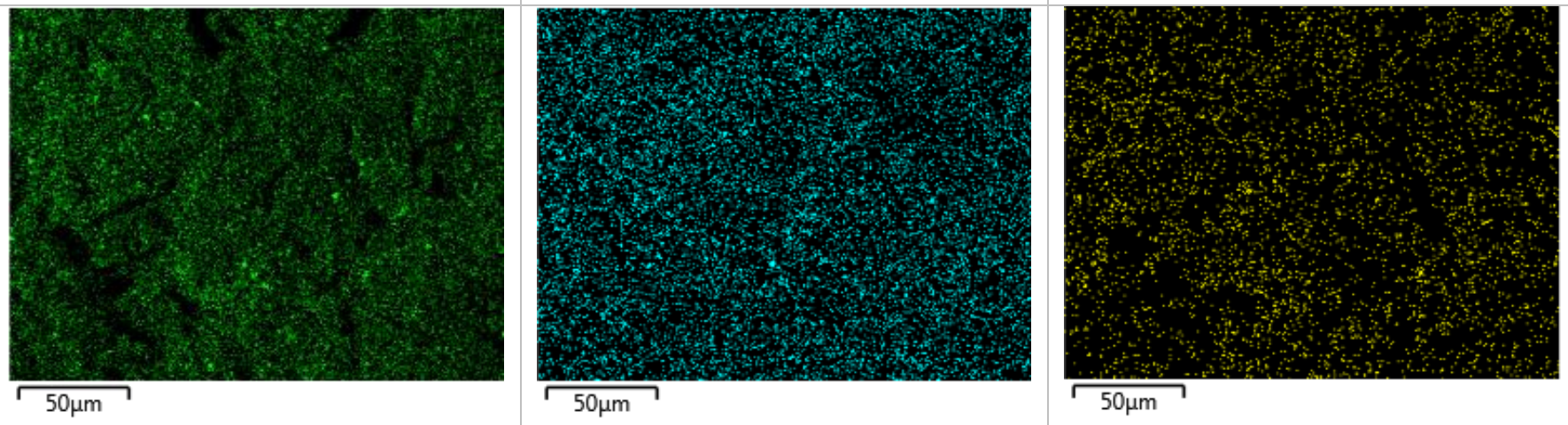

Fig. 2: Elemental mapping of the prepared sensors: (a) sensor 4, (b) sensor 5; (c) sensor 6 and (d) sensor 7. Green (Oxygen), Terquaz (Sulphur), and Yellow (Nitrogen)

\section{Effect of $\mathbf{p H}$}

The effect of $\mathrm{pH}$ on the response of the fabricated sensors showed that the $\mathrm{pH}$-independent region lies between 5.5 and 9.5. At lower $\mathrm{pH}$ values (from 0 to 5.5), protonation of the ionophore in the optimum electrode (sensor 6) causes an increase of the potential about the order of magnitude from 36 to $86 \mathrm{mV}$. While at higher $\mathrm{pH}$ values (from 9.5 to 14 ) the potential decreases from 27 to $-17 \mathrm{mV}$ is due to hydroxide interference $[5,19,30]$.

\section{Selectivity and formation constant}

Using sensor 6 , SSM was used to determine the selectivity coefficient, $K_{S a l, J}^{\text {pot }}$, over the most lipophilic anions, the hydrogen bonding forming species, and those having similar structura e. Sensor 
6 exhibited good selectivity over all species, even that having similar structure such as benzoate. To relate the selectivity to the binding strength, formation constants were measured by sandwich membrane method [33]. Complete agreement is obtained between the results of formation constant and selectivity, where the most interfering species show the highest formation constant species and vice versa, Table 3 .

Table 3: The logarithmic values of the selectivity coefficients and formation constant.

\begin{tabular}{ccc} 
Anion & $\log K_{\text {Sal, }}^{\text {pot }}$ & $\log \beta_{I L_{n}}$ \\
\hline Salicylate $^{-}$ & 0.00 & 4.50 \\
$\mathrm{SO}_{4}^{-}$ & -2.18 & 2.00 \\
$\mathrm{Cl}^{-}$ & -3.35 & 2.28 \\
$\mathrm{Br}^{-}$ & -2.61 & 2.22 \\
$\mathrm{NO}_{2}^{-}$ & -2.10 & 2.80 \\
$\mathrm{I}^{-}$ & -0.88 & 3.17 \\
Benzoate $^{-}$ & -1.77 & 3.00 \\
$\mathrm{SCN}^{-}$ & -0.40 & 1.98 \\
$\mathrm{ClO}_{4}^{-}$ & -0.53 & 3.70
\end{tabular}

\section{Theoretical Studies}

Theoretical studies were performed here to ensure selectivity pattern obtained by SSM. Also, these theoretical studies for the first time could be used to calculate the non-linear optical (NLO) properties of the different formed anion-thiourea complexes. A relation between the selectivity pattern and NLO properties of the different complexes is proposed. This relationship is the first time to be established to use ion selective electrodes for predicting new promising candidates of NLO properties. 
Comparison of NLO properties of formed anion-thiourea complexes and urea as a reference will be mentioned.

\section{H-bond formation and binding energy}

The structures of the studied complexes, anions, and the neutral ligand are obtained using B3LYP/6-31G**, where the final geometries and numbering system are presented in Fig. 3. All complexes are stabilized by the H-bond formed between negatively charged oxygen atoms of salicylate, nitrite, benzoate and perchlorate and the $\mathrm{H}$-atoms of the four $\mathrm{N}-\mathrm{H}$ of the neutral ligand. The lengths of the H-bonds of the four complexes are presented in Fig. 3. In our case, the binding energy B.E., of the four complexes is calculated as B.E. $=E_{\text {complex }}\left(E_{\text {anion }}+E_{\text {ligand }}\right)$. As the computed B.E. decreases, the stability of the complex increases and the selectivity increases. From the results in Tables 4 and 5, the order of increasing selectivity is L-perchlorate $<$ L-salicylate $=$ L-Benzoate $<$ Lchloride $<$ L-thiocyanate, which confirm salicylate selectivity with perchlorate interference.

A

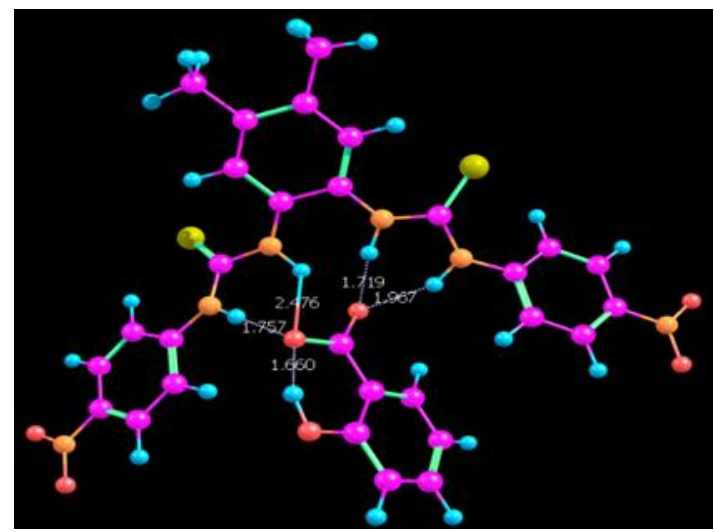

B

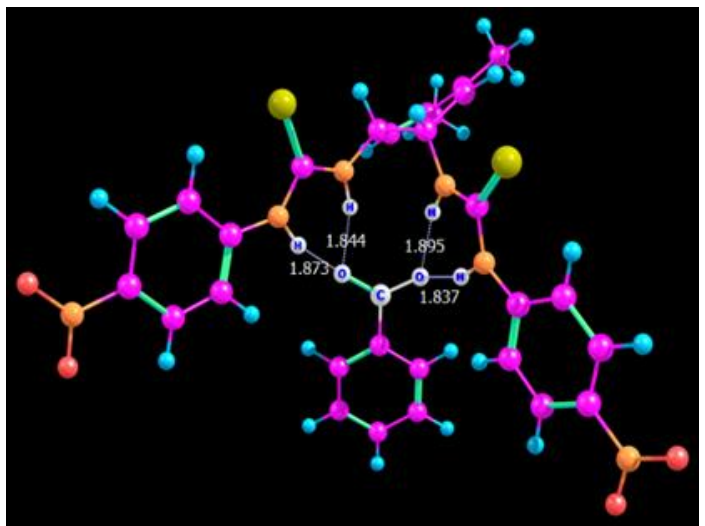


C

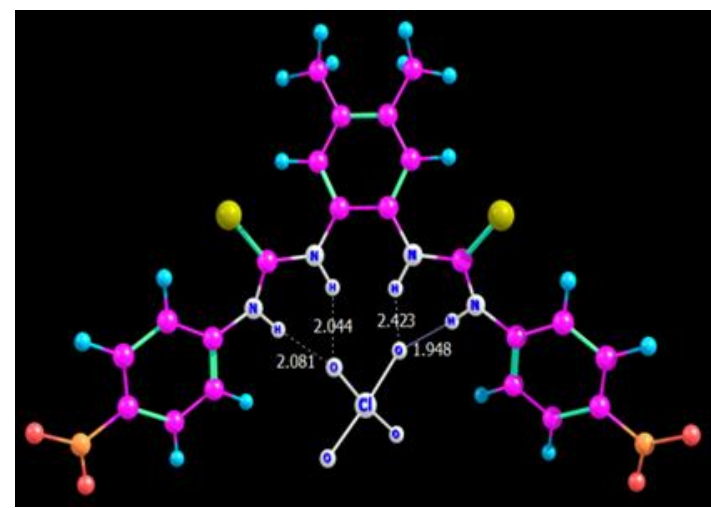

$\mathrm{D}$

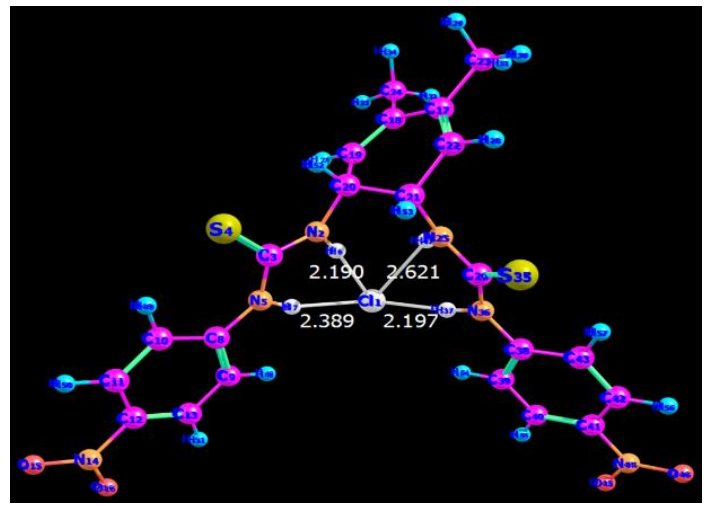

$\mathrm{E}$

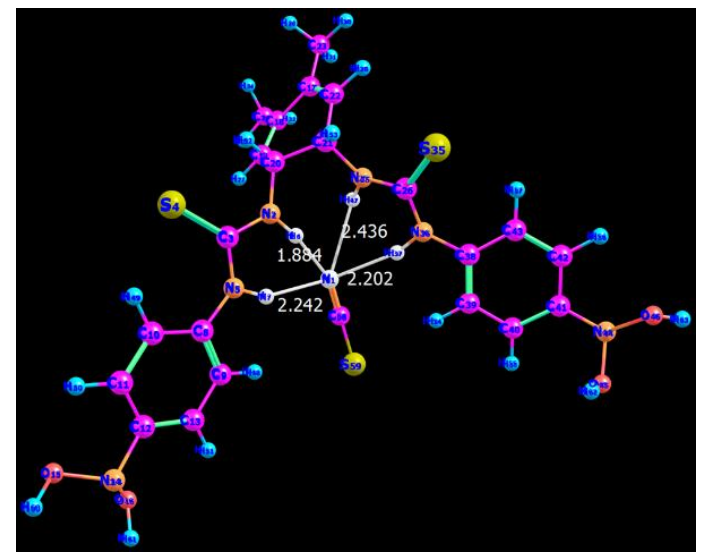

Fig. 3: Structures of different anion-thiourea complexes showing H-bonds; (A) L-salicylate, (B) Lbenzoate, (C) L-perchlorate, (D) L-Chloride, and (E) L-SCN.

\section{Global reactivity descriptors}

Tables 4 and 5 presents the different descriptors of Energy (electron affinity (A), ionization potential (I), chemical potential (V), electronegativity (X), LUMO, HOMO, and energy gap $\left(E_{g}\right)$ ), and physical properties descriptors (chemical hardness $(\eta)$ and chemical softness (S)) which are described as reported before [34-37]. Also, Table 5 shows the energies of the frontier molecular orbitals (FMO) for the complexes under study, which were calculated using the B3LYP/6-31G** level of theory. Electron withdrawing and donating abilities are characterized by LUMO and HUMO energies, respectively [34-37]. 
Table 4: Global reactivity descriptors of the different thiourea- anion complexes

\begin{tabular}{cccccc} 
& L-Salicylate & L-Benzoate & L-perchlorate & L-Chloride & L-thiocyanate \\
\hline $\mathrm{E}_{\mathrm{T}}, \mathrm{au}$ & -2772.648 & -2697.602 & -3036.761 & -2737.6 & -2270.6 \\
B.E., Kcal & 681.5 & 681.5 & 52.1 & 774.3 & 1413.2 \\
$\mathrm{E}_{\mathrm{HOMO}}, \mathrm{au}$ & -0.2295 & -0.1231 & -0.2514 & -0.1272 & -0.1095 \\
$\mathrm{E}_{\mathrm{LUMO}}, \mathrm{au}$ & -0.1015 & -0.0076 & -0.0394 & -0.0068 & 0.0509 \\
$\mathrm{I}, \mathrm{eV}$ & 6.242 & 3.348 & 6.838 & 3.459 & 2.978 \\
$\mathrm{~A}, \mathrm{eV}$ & 2.761 & 0.207 & 1.072 & 0.185 & -1.348 \\
$\chi, \mathrm{eV}$ & 4.502 & 1.778 & 3.955 & 1.822 & 0.815 \\
$\eta, \mathrm{eV}$ & 1.741 & 1.571 & 2.883 & 1.637 & 2.163 \\
$\mathrm{~S}, \mathrm{eV}$ & 0.182 & 0.194 & 0.173 & 0.305 & 0.231 \\
$v, \mathrm{eV}$ & -4.502 & -1.778 & -3.955 & -1.822 & -0.815 \\
$\omega, \mathrm{eV}$ & 2.908 & 3.012 & 2.205 & 27.798 & 0.251
\end{tabular}

Table 5: HUMO and LUMO of different thiourea-anion complexes with a schematic representation of their energies and energy gaps.

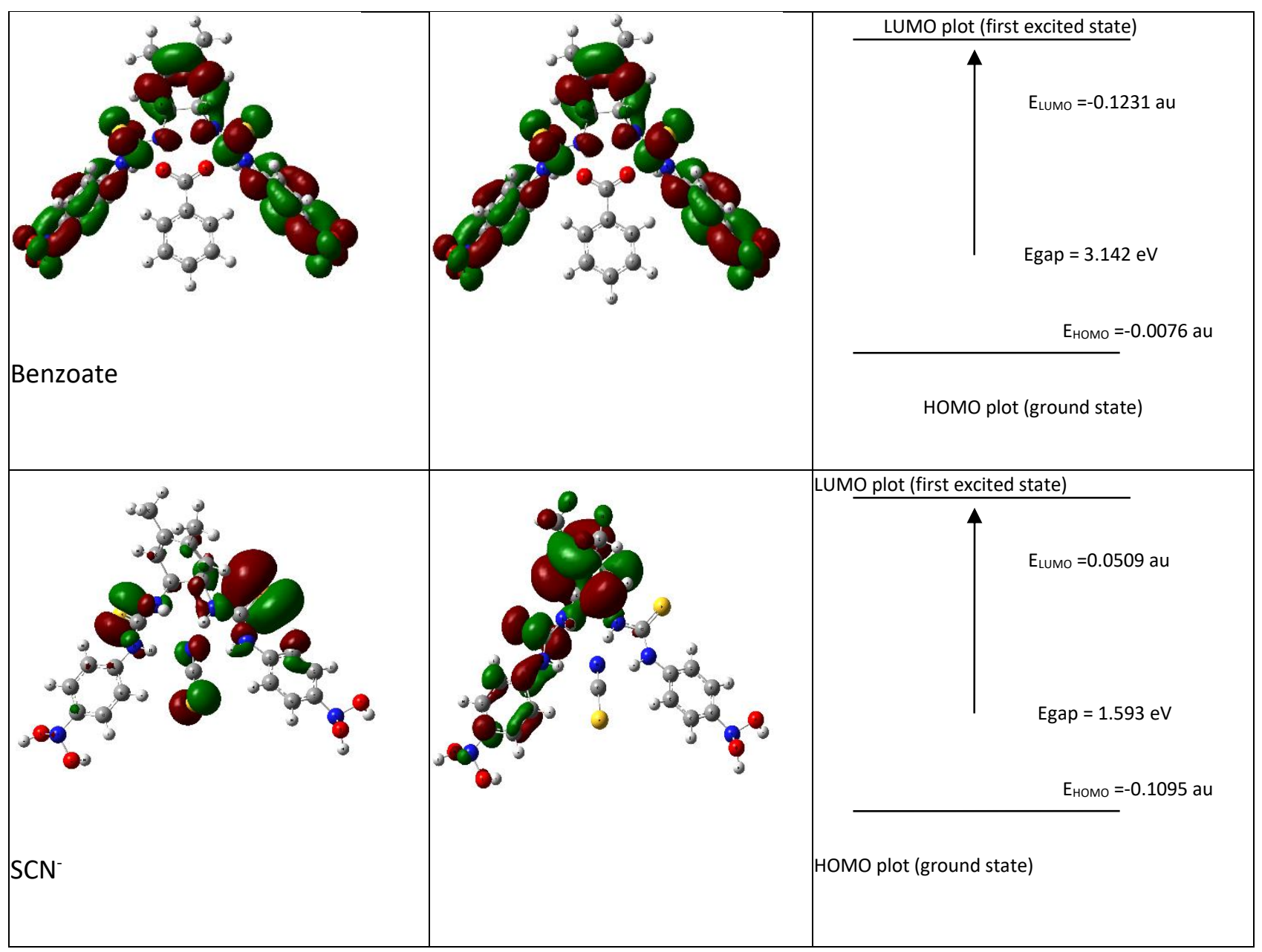




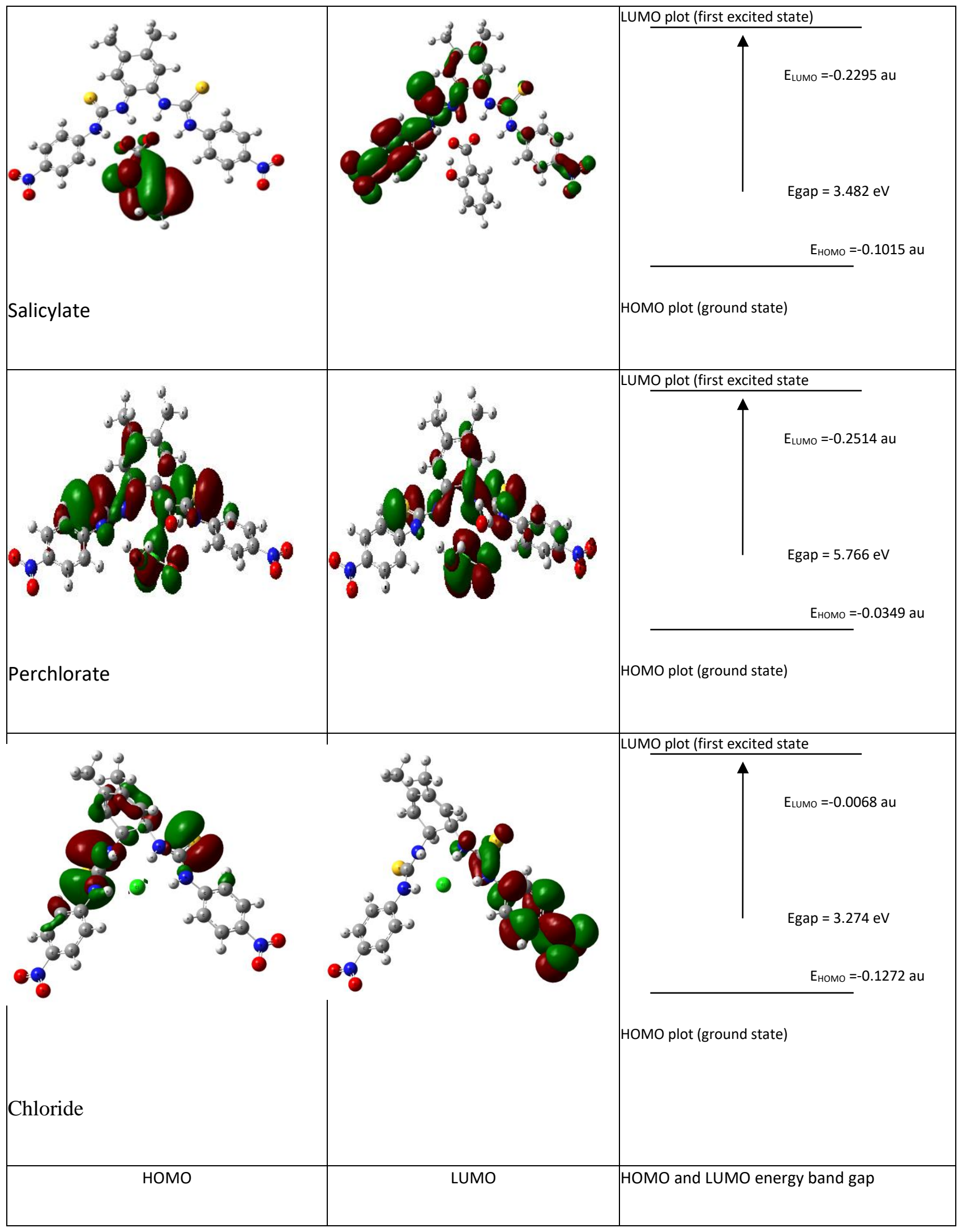

3. Non-linear optical properties (NLO) 
The NLO theoretical calculations may be regarded as preliminary studies for selectivity investigation of new ionophores bearing of NLO properties. The polarizability and hyperpolarizability for the different anion-ionophore complexes are calculated using B3LYP/6-31G**. Table S1 shows the different NLO parameters of the mean first-order hyperpolarizability $(\beta)$, the anisotropy of the polarizability $\Delta \alpha$, the mean polarizability $\alpha$ and total static dipole moment $(\mu)$ of the studied complexes. The polarizabilities and firstorder hyperpolarizabilities are informed in atomic units (a.u.), converted into electrostatic units (esu) using $8.6393 \times 10^{-33}$ esu for $\beta$ and $0.1482 \times 10^{-24}$ esu for $\alpha$ as conversion factors [46], and these values are compared to those of NLO standard prototype, [47]. The hyperpolarizability $\beta$ is the most important factor in NLO systems.

Table 6: Non-linear optical properties (NLO) of the studied complexes.

$\begin{array}{llll} & \mu, \mathrm{D} & \mathrm{DR} . & \beta_{\mathrm{HRS}} \\ \text { L-Salicylate } & 10.128 & 0.05 & 117.34 \\ \text { L-Perchlorate } & 12.715 & 0.30 & 74.82 \\ \text { L-Benzoate } & 9.465 & 0.08 & 308.14 \\ \text { L-Chloride } & 9.540 & 0.12 & 54.65 \\ & & & \\ \text { L-Thiocyanate } & 1.045 & 0.44 & 57.82\end{array}$


Also, to relate the selectivity pattern obtained by the ion-selective electrode to NLO properties, Hyper-Rayleigh scattering ( $\left.\beta_{\mathrm{HRS}}\right)$ and the depolarization ratio (DR.) is calculated. The variation of these parameters shown in Table 6 can be rationalized by complexation and structural evidence [48]. The highest value of $\beta_{\text {HRS }}$ for benzoate and salicylate confirms short bond length between these anions and thiourea ligand which confirm their strong complexation and higher selectivity $[48,49]$. The lowest value of DR. should be obtained for the more selective ion, which is shown in the Table 6 for salicylate and perchlorate. These data confirm the salicylate selectivity with some interference by benzoate and perchlorate.

\section{Response time and lifetime}

Response time is the time taken from the dipping of the electrode in the solution till achieving the equilibrium potential [44], and it was measured by the successive immersions of the electrode in a series of salicylate solutions. It was observed that the sensor reaches steady state potential in a very short time, 5 seconds, for the sensors 6-7, and 1 minute for sensor 8, Fig. 4. It was found that sensor 6 could be used for 2 months without significant deviation in the slope or the detection limit. After this time, the response characteristics started to diminish which may be due to the dissolution of the paste components to the bathing solution $[44,45]$. 


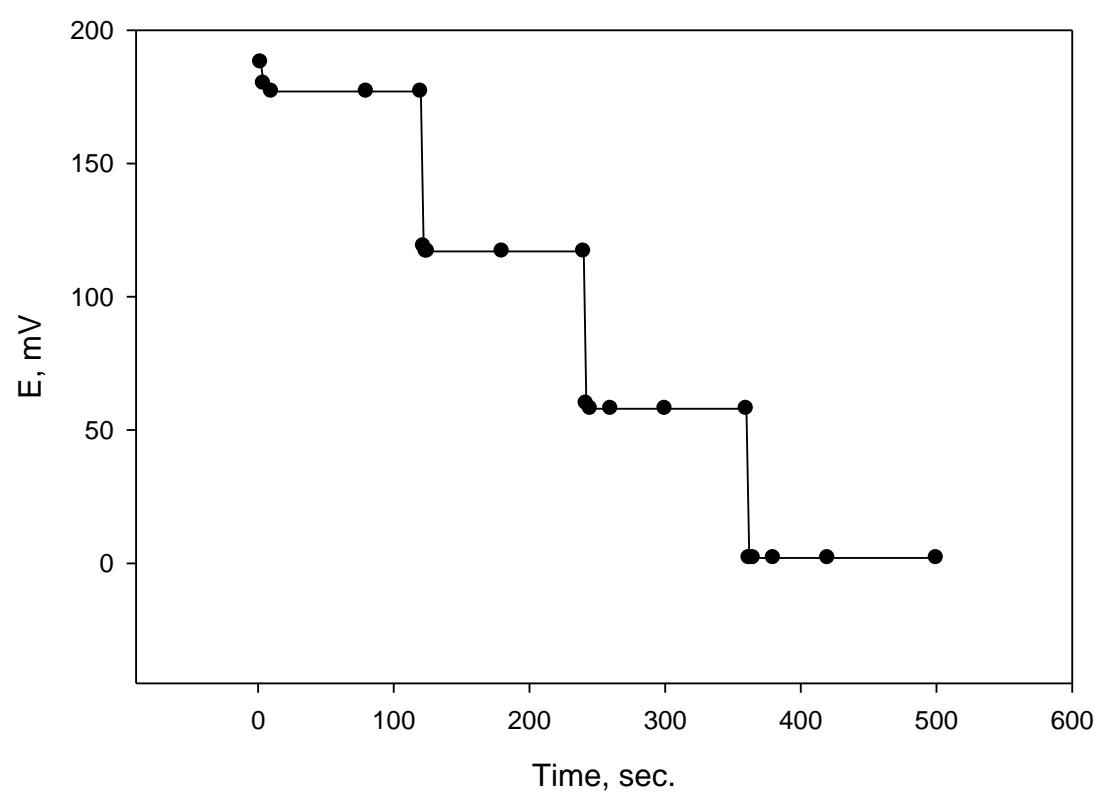

Fig. 4: response time of sensor 6.

\section{Analytical applications}

Sensor 6 was used for determination of salicylate in pharmaceutical formulations. Results were compared to that obtained by reference method [5,39]. Table 7 showed the applicability of the proposed method, where high recovery values were obtained.

Table 7: Determination of Aspocid ${ }^{\circledR}$ and Aspirin $®$ by proposed and previous methods.

\begin{tabular}{cccc} 
& [39], mM & [5], mM & Sensor 6, mM \\
\hline Aspocid ${ }^{\circledR}$ & 9.1 & 9.4 & 9.5 \\
Aspirin ${ }^{\circledR}$ & 8.3 & 7.9 & 7.5
\end{tabular}

Comparing the results of the obtained sensor to that of some previously reported thiourea-based sensor [27], Table 8, shows the improvement in the detection limit, application concentration range and response time. 
Table 8: comparison between the response characteristics of this work and previously reported thiourea-based sensor.

Current work

Response time

Detection limit

Conc.range
$-0.88$

$-0.53$

$20 \mathrm{sec}$

[27]

$-0.8$

$30 \mathrm{sec}$

$1.0 \times 10^{-5}$

$9.0 \times 10^{-5}$

$10^{-1}-10^{-5}$

$10^{-5}-10^{-1}$

\section{Conclusion}

Thiourea-based carbon paste electrodes were constructed for salicylate determination in solutions containing the salicylate-containing pharmaceutical preparations, Aspirin ${ }^{\circledR}$, and Aspocid®. The response mechanism was based on the ability and strength of the hydrogen bonding between the anion and the thiourea ionophore. The constructed carbon paste electrodes were modified with graphene oxide, reduced graphene oxide and multiwalled carbon nanotubes, which in turn improved the selectivity over anions that can form hydrogen bonding and structurally similar anions; e.g. $\log K_{S a l, S O_{4}^{2-}}^{\text {pot }}=-2.18, \log K_{\text {Sal,benzoate }}^{\text {ot }}=-1.7$. The response mechanism and selectivity pattern were confirmed with DFT calculations and can be related to the nonlinear optical properties of the formed complexes. Some of the formed complexes exhibited promising optical properties.

\section{Authors have no conflict of interest to declare.}




\section{References}

[1] N.S. Palikhe, S.H. Kim, H.S. Park, What do we know about the genetics of aspirin intolerance, 33(2008) (5), 465-72

[2] S. Shahrokhian, A. Hamzehloei, M. Bagherzadeh. PVC-Based Mn(III) Porphyrin Membrane-Coated Graphite Electrode for Determination of Histidine, 74(2002), 3312-3320

[3] A. L. Sun, Y. Q. Chai, R. Yuan, G. F. Gui, Chin. J. Highly Selective Salicylate Membrane Electrode Based on N,N'-(Aminoethyl)ethylenediamide Bis(2-salicylideneimine) Binuclear Copper(II) Complex as Neutral Carrier, 24(2006), 894- 898.

[4] "Acetylsalicylic Acid." UXL Encyclopedia of Science. . Encyclopedia.com. 13 Feb. $2017<$ http://www.encyclopedia.com>.

[5] A.L. Sun, Y.Q. Chai, R.G.F. Gui, Chin. Highly Selective Salicylate Membrane Electrode Based on N,N'(Aminoethyl)ethylenediamide Bis(2-salicylideneimine) Binuclear Copper(II) Complex as Neutral Carrier, 24(2006), 894 .

[6] T.G. Moore, M.J. Joseph, B.W. Allen, L.A. Coury, Enzymically Amplified Voltammetric Sensor for Microliter Sample Volumes of Salicylate, 67(1995), 1896.

[7] J.B. Mowry, D.A. Spyker, D.E. Brooks, N. McMillan, J.L. Schauben, 2014 Annual Report of the American Association of Poison Control Centers' National Poison Data System (NPDS): 32nd Annual Report., 53(2015)(10), 962.

[8] P. C. Damiani, M. D. Borraccetti, A. C. Olivier, Anal. Chim. Acta., 2002, 471, 87.

[9] I. M. Scott, H. Yamamoto. Phytochem., 1994, 37,335.

[10] M. S. Marcelo, G. T. Marcello, J. P. Ronei,Analysis of liposomes, 68(2006),1707-1212

[11] G. A. Rivas, J. M. Calatayud, FIA-AAS determination of salicylic acid by a solid-phase reactor of copper carbonate incorporated in polyester resin beads, 42(1995), 1285. 
[12] L. Lu, X. Zhu, X. Qiu, H. He, J. Xu, X. Wang, Int. J. graphene oxid/multi walled carbon nanotubes composites as an enhanced sensing platform for voltametric determination of salcylic acid , 9(2014), 8057.

[13] S. Croubels, A. Maes, K. Baert, P. De Backer, Anal. Chim. Acta, 2005, 520, 179.

[14] E. Bakker, Electroanalysis with Membrane Electrodes and Liquid-Liquid Interfaces, 88(2016), 395.

[15] I.S. vancara, K. Vytras, K. Kalcher, A. Walcarius, J. Wang, Carbon Paste Electrodes in Facts, Numbers, and Notes: A Review on the Occasion of the 50-Years Jubilee of Carbon Paste in Electrochemistry and Electroanalysis, 21(2009)(1), 7.

[16] Sh. A. Zaidi, Int. J. grapheme; a comperehensive review on its utilization in carbon paste electrodes for improved sensor performances, 8(2013), 11337.

[17] I. Švancara, K. Vytřas, J. Barek, J. Zima, Carbon Paste Electrodes in Modern Electroanalysis, 31(2001)(4), 311.

[18] M.N. Ayanoglu, H. E.K. Ertirin, A.D. Ozel, O. Sahin, M. Y1lmaz, E. K1lıc, Salicylate Ion-Selective Electrode Based on a Calix[4]arene as Ionophore, 27(2015), 1676.

[19] I.M. Isa, N. M. Sohaimi, N. Hashim, A. Kamari, A. Mohamed, M. Ahmad, S.A. Ghani, Suyanta, Int. J. determination of salicylate ion by potentiometric membrane electrode, 8(2013), 2112.

[20] M. Mazloum-Ardakani, P. Pourhakkak, M. Salavati-Niasari, M.A. Karimid, M.H. Mashhadizadeh, J. Braz. Efficient Dehydrogenation of Formic Acid Using an Iron Catalyst22(2011), 30.

[21] E.P. Luo, Y.Q. Chai, R. Yuan, J.Y. Dai, L. Xu, Highly salicylate-selective membrane electrode based on a new thiomacrocyclic Schiff base complex of binuclear copper(II) as neutral carrier, 249(2009), 615.

[22] S. O. Kang, J. M. Linares, D. Powell, D. VanderVelde, K. Bowman-James, J. Am. New Polyamide Cryptand for Anion Binding125(2003), 10152.

[23] S.I. Kondo, Y. Hiraoka, N. Kurumatani, Y. Yano, Carborane acids. New "strong yet gentle" acids for organic and inorganic chemistry, 1720(2005) 
[24] D.H. Lee, H.Y. Lee, K.H. Lee, J.I. Hong, Selective anion sensing based on a dual-chromophore approach $\dagger, 1188(2001)$

[25] G.M. Kyne, M.E. Light, M.B. Hursthouse, J. de Mendoza, J.D. Kilburn, J. Strongly Acidic and HighTemperature Hydrothermally Stable Mesoporous Aluminosilicates with Ordered Hexagonal Structure, 1258(2001).

[26] F.M. Abdel-Haleem, Highly selective thiourea-based bulk optode for determination of salicylate in spiked urine samples, Aspirin ${ }^{\circledR}$ and Aspocid ${ }^{\circledR}, 233(2016), 257$.

[27] Chaegyeong Lee, Junghwan Kim, Dong Wan Kim, Shim Sung Lee, Jineun Kim, and Jae Sang KimBull. Korean Chem. Soc. 2007, Vol. 28, No. 12, 2466-70.

[28] (a) S. Natorajan, G. Shanmugam, S.A. Martin, Cryst. Res. Technal. 2008, 43,561. (b) D.S. Chemia, J. Zysss, Nonlinear Optical Properties of Organic Molecules and Crystals Academic Press, Orlando,FL,1987. (c) D.S. Bradshow, D.L. Andrews, J. Nonlinear Opt. Phys. Matter, 2009, 18, 285.

[29] H. Moustafa, M.E. Elshakre, S. Elramly, Electronic structure and nonlinear optical properties (NLO) of 2,4-di-aryl-1,5-benzothiazepine derivatives using DFT approach, 1136(2017), 25.

[30] A.I. Vogel, Quantitative Inorganic Analysis, Longman, London, S. E. 1st ed. Vol. 18. 1930.

[31] H. Shin, K.K. Kim, A. Benayad, S. Yoon, H.K. Park, I. Jung, M.H. Jin, H. Jeong, J.M. Kim, J. Choi, Y.H. Lee, Efficient Reduction of Graphite Oxide by Sodium Borohydride and Its Effect on Electrical Conductance, 19(2009), 1987.

[32] M.S. Rizk, F.M. Abdel-Haleem, M. Saad, Development of new potentiometric sensors for the determination of proguanil hydrochloride in serum and urine, 27(2016), 857.

[33]. G.W.T.M.J. Frisch, H.B. Schlegel, G.E. Scuseria, M.A. Robb, J.R. Cheeseman, G. Scalmani, V. Barone, B. Mennucci, G.A. Petersson, H. Nakatsuji, M. Caricato, X. Li, H.P. Hratchian, A.F. Izmaylov, J. Bloino, G. Zheng, J.L. Sonnenberg, M. Hada, M. Ehara, K. Toyota, R. Fukuda, J. Hasegawa, M. Ishida, T. Nakajima, Y. 
Honda, O. Kitao,H. Nakai, T. Vreven, J.A. Montgomery Jr., J.E. Peralta, F. Ogliaro, M. Bearpark, J.J. Heyd, E. Brothers, K.N. Kudin, V.N. Staroverov, R. Kobayashi, J. Normand, K. Raghavachari, A. Rendell, J.C. Burant, S.S. Iyengar, J. Tomasi, M. Cossi, N. Rega, J.M. Millam, M. Klene, J.E. Knox, J.B. Cross, V. Bakken, C. Adamo, J. Jaramillo, R. Gomperts, R.E. Stratmann, O. Yazyev, A.J. Austin, R. Cammi, C. Pomelli, J.W. Ochterski, R.L. Martin, K. Morokuma, V.G. Zakrzewski, G.A. Voth, P. Salvador, J.J. Dannenberg, S. Dapprich, A.D. Daniels, O. Farkas, J.B. Foresman, J.V. Ortiz, J. Cioslowski, and D. J. Fox, Gaussian Inc., Wallingford, CT (2009).

[34] T. Schaefer, T.A. Wildman, S.R. Salman, J. Am. An electrically neutral .sigma.-sulfuranyl radical from the homolysis of a perester with neighboring sulfenyl sulfur: 9-S-3 species, 102(1980), 107.

[35] T. Schaefer, S.R. Salman, T.A. Wildman, P.D. Clark, Can. JConformational consequences of intramolecular hydrogen bonding by $\mathrm{OH}$ to the directional lone-pair of sulfur in derivatives of methyl phenyl sulfide, diphenyl sulfide, and diphenyl disulfide, 60(1982), 342.

[36] A.D. Becke, J. Density-functional thermochemistry. III. The role of exact exchange, 98(1993), 5648.

[37] S.E. Ulic, C.O.D. Védova, A. Hermann, H.G. Mack, H. Oberhammer, J. Phys. Length-Dependent Optical Effects in Single Walled Carbon Nanotubes $\uparrow$, 112(2008), 6211.

[38] A.E. Reed, F. Weinhold, J. Natural bond orbital analysis of near-Hartree-Fock water dimer, 78(1983), 4066.

[39] T. Verbiest, K. Clays, V. Rodriguez, Second-Order Nonlinear Optical CharacterizationsTechniques: an Introduction, CRC Press, New York, 2009.

[40] R. Bersohn, Y.H. Pao, H.L. Frisch, J. Chem. Phys. 1966, 45, 3184-3198.

[41] P. Trinder, Rapid determination of salicylate in biological fluids, 57(1954)(2), 301.

[42] V. Georgakilas, M. Otyepka, A.B. Bourlinos, V. Chandra, N. Kim, K.Ch. Kemp, P. Hobza, R. Zboril, K.S. Kim, Functionalization of Graphene: Covalent and Non-Covalent Approaches, Derivatives and Applications , 112(2012), 6156. 
[43] Y. Liu, X. Dong, P. Chen, Biological and chemical sensors based on graphene materials, 41(2012), 2283.

[44] E. Bakker, P. Bühlmann, E. Pretsch, Carrier-Based Ion-Selective Electrodes and Bulk Optodes. 1. General Characteristics, 8(1997), 3083-3132

[45] N.T. Abdel Ghani, R.M. El Nashar, F.M. Abdel-Haleem, Computational Design, Synthesis and Application of a New Selective Molecularly Imprinted Polymer for Electrochemical Detection, 28(2006)(7), 1530.

[46] A. A. Abdel Aziz, F. M. Elantabli, H. Moustafa, S. M. El-Medani, J. Molec. Structure 1141 (2017) 563576

[47] A.A. Abdel Aziz, F.M. Elantabli, H. Moustafa, S.M. El-Medani, Spectroscopic, DNA binding ability, biological activity, DFT calculations and non linear optical properties (NLO) of novel Co(II), $\mathrm{Cu}(\mathrm{II}), \mathrm{Zn}(\mathrm{II})$, Cd(II) and $\mathrm{Hg}(\mathrm{II})$ complexes with ONS Schiff base 1141(2017), 563.

[48] B. Champagne, A. Plaquet, J. Pozzo, V. Rodriguez, F. Castet, Nonlinear Optical Molecular Switches as Selective Cation Sensors, J. Am. Chem. Soc. 2012, 134, 8101-8103.

[49] A. Plaquet, B. Champagne, F. Castet, Nonlinear Optical Molecular Switches for Alkali Ion Identification, Molecules 2014, 19, 10574-10586 